\title{
DETECÇÃO MOLECULAR DE TRYPANOSOMA CRUZI EM ÓRGÃOS DE MAMÍFEROS SILVESTRES DA FAUNA DA MATA ATLÂNTICA - BAHIA
}

\author{
Taise Cristina Santa Barbara Silva Queiroz ${ }^{1}$; Aristeu Vieira da Silva ${ }^{2}$; Caroline Araújo \\ da Silva ${ }^{3}$ e Eddy José Francisco de Oliveira ${ }^{4}$ \\ 1. Bolsista PIBIC/CNPq, Graduanda em Bacharelado em Ciências Biológicas, Universidade Estadual de Feira de Santana, \\ taii.cristina@hotmail.com \\ 2. Orientador, Departamento de Ciências Biológicas, Universidade Estadual de Feira de Santana, e-mail: \\ aristeuvsilva@uefs.br \\ 3. Participante do Grupo de Pesquisa em Zoonoses e Saúde Pública, Graduanda em Bacharelado em Ciências Biológicas, \\ Universidade Estadual de Feira de Santana, e-mail: carol.adp@ hotmail.com \\ 4. Participante do Grupo de Pesquisa em Zoonoses e Saúde Pública, Departamento de Ciências Biológicas, Universidade \\ Estadual de Feira de Santana, e-mail: eddyfo@gmail.com
}

PALAVRAS-CHAVE: Protozoário; Zoonose; Silvestres.

\section{INTRODUÇÃO}

O Trypanosoma cruzi é conhecido mundialmente por ser o agente etiológico da Doença de Chagas, sendo endêmica no México e nas Américas Central e do Sul (Machado et al., 2012). Na América, a incidência de tripanossomíase é aproximadamente 41.200 casos por ano, e em média o parasito causa 12.500 mortes a cada ano (Ramírez et al., 2012). O Trypanosoma tem ampla distribuição podendo infectar quase todos os tecidos de hospedeiros, pertencentes a oito ordens de mamíferos (Rocha et al., 2013). A Mata Atlântica é um dos biomas com a maior riqueza de mamíferos (De Carvalho \& De Oliveira, 2015).

É importante o levantamento de informações sobre os potenciais reservatórios de $T$. cruzi, e assim, contribuir para estabelecimento de padrões adequados de vigilância epidemiológica. Ademais, alguns estudos mostram que a reação em cadeia da polimerase (PCR) é melhor técnica para detectar T. cruzi no sangue de humano e de cão (Miyamoto et al., 2006), sendo que os ensaios de PCR de minicírculos de kDNA são de alta sensibilidade (Ortiz et al., 2012). Dessa forma, o objetivo do trabalho foi avaliar a presença e a frequência de Trypanosoma cruzi em mamíferos silvestres provenientes da Mata Atlântica, Bahia, utilizando a técnica de PCR-kDNA no diagnóstico molecular do protozoário.

\section{MATERIAL E MÉTODOS}

A amostragem concentrou-se na Mata Atlântica, sendo que a origem dos mamíferos silvestres foram os municípios da Bahia: Elísio Medrado (oito animais), Ibirapitanga (três animais), Igrapiúna (37 animais), Iraquara (um animal), Lençóis (um animal), Nilo Peçanha (dois animais) e Varzedo (17 animais). O trabalho teve parecer favorável pelo Comissão de Ética no Uso de Animais (CEUA) da Universidade Estadual de Feira de Santana (UEFS) (Processo $n^{\circ}$ 011/2016). A detecção molecular foi realizada para investigação de $T$. cruzi em pool de tecidos de diferentes órgãos (encéfalo, coração, pulmão, rins, baço ou/e fígado) de 69 animais silvestres das ordens: 18 Chiroptera, 22 Didelphimorphia e 29 Rodentia.

Primeiramente, foi realizado o processamento das amostras de pool, seguida a extração de DNA utilizando o kit comercial PureLink®GenomicDNA. Depois, no equipamento Nanodrop foram calculadas a concentração e a pureza do DNA a $260 \mathrm{~nm}$ e 280 $\mathrm{nm}$. Para detecção molecular do protozoário foi realizada a técnica de PCR, sendo que cada alíquota do produto da extração de DNA foi submetida à amplificação específica do fragmento com $330 \mathrm{pb}$, que corresponde a regiões variáveis do kDNA minicírculo (Vago et al., 2000). Para isso, foram utilizados os primers, o 121 (5'AAATAATGTACGGG(T/G)GAGATGCATGA-3') e $\quad$ o 122 GGTTCGATTGGGGTTGGTGTAATATA-3'), cuja as condições variavam na tentativa de encontrar uma reação padrão da detecção molecular de T. cruzi (Tabela 1). 
Tabela 1. Condições de reação em cadeia da polimerase avaliadas na detecção molecular de Trypanosoma cruzi.

Condições de reação

\begin{tabular}{lllllll}
$\begin{array}{l}\text { Componentes do mix de reação/ } \\
\text { temperatura de anelamento }\end{array}$ & $\mathbf{1}$ & $\mathbf{2}$ & $\mathbf{3}$ & $\mathbf{4}$ & $\mathbf{5}$ & $\mathbf{6}$ \\
\hline Tampão 10X $(\mu \mathrm{l})$ & 2,5 & 2,5 & 2,5 & 2,5 & 2,5 & 2,5 \\
$\mathrm{MgCl}_{2}(50 \mathrm{mM})(\mu \mathrm{l})$ & 0,75 & 0,75 & 0,75 & 1 & 0,75 & 0,75 \\
$\mathrm{dNTP}(2,5 \mathrm{mM})(\mu \mathrm{l})$ & 1,5 & 1,5 & 1 & 1 & 1 & 1 \\
Primer $121(\mu \mathrm{l})$ & 1,5 & 1 & 0,5 & 0,5 & 0,5 & 0,5 \\
Primer $122(\mu \mathrm{l})$ & 1,5 & 1 & 0,5 & 0,5 & 0,5 & 0,5 \\
Taq $(5 \mathrm{U} / \mu \mathrm{l})(\mu \mathrm{l})$ & 0,25 & 0,25 & 0,2 & 0,2 & 0,2 & 0,2 \\
$\mathrm{H}_{2} \mathrm{O}(\mu \mathrm{l})$ & 15 & 16 & 18,55 & 18,55 & 18,55 & 17,55 \\
TOTAL $(\mu \mathrm{l})$ & 23 & 23 & 24 & 24 & 24 & 23 \\
Amostra de DNA $(\mu \mathrm{l})$ & 2 & 2 & 1 & 1 & 1 & 2 \\
Anelamento & $63^{\circ} \mathrm{C}$ & $63^{\circ} \mathrm{C}$ & $63^{\circ} \mathrm{C}$ & $63^{\circ} \mathrm{C}$ & $65^{\circ} \mathrm{C}$ & $63^{\circ} \mathrm{C}$ \\
\hline
\end{tabular}

As reações foram realizadas no termociclador programado com: primeiro passo de 3 min a $94{ }^{\circ} \mathrm{C}$; seguido por 35 ciclos com desnaturação a $94{ }^{\circ} \mathrm{C}$ por $45 \mathrm{~s}$, anelamento a $63{ }^{\circ} \mathrm{C}$ por $45 \mathrm{~s}$ e a fase de extensão a $72{ }^{\circ} \mathrm{C}$ durante $45 \mathrm{~s}$; e por último $72{ }^{\circ} \mathrm{C}$ por $10 \mathrm{~min}$. A seguir, os

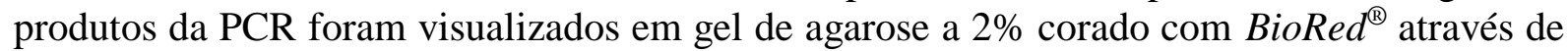
um transiluminador de luz UV e do programa LPix Image da Loccus Biotecnologia.

As frequências de positividade para a presença de Trypanosoma cruzi foram comparadas entre as ordens e entre as localidades pelo teste não paramétrico de Qui-quadrado e o teste $\mathrm{G}$ de Willians, considerando-se os resultados significativos com valores de $\mathrm{P}<0,05$. Ademais, foi elaborado mapa com as coordenadas dos locais de amostragem realizando o georreferenciamento usando software QGIS 2.14.12-Essen, sendo realizada estimativa Kernel para inferir os locais com maior ocorrência dos reservatórios do protozoário.

\section{RESULTADOS E DISCUSSÃO}

Foram realizados vários métodos de PCR de kDNA, na primeira condição de reação houve amplificação de uma (DM 0477) com a concentração de 1,7 ng/ $\mu$ de DNA, essa primeira condição de reação foi repetida com a concentração do DNA extraído das amostras diluídas a uma concentração de 1,7 ng/ $\mu$, havendo amplificação de DM 0477 com a formação de uma banda entre $300 \mathrm{pb}$ e $400 \mathrm{pb}$ do produto esperado e outra banda com mais de $400 \mathrm{pb}$.

Concentrações mais elevadas de primers podem promover o acúmulo de produtos não específicos e dímero de primer, que podem servir como substratos para PCR, competindo com os produtos desejados pelos dNTPs, Taq e iniciadores usados na PCR (Innis \& Gelfand, 2012). Dessa forma, foi realizada uma segunda condição de PCR, em que houve a amplificação da maioria das amostras examinadas e é possível visualizar bandas inespecíficas.

Em uma investigação de triatomíneos da Bahia por infecção por T. cruzi utilizando o método de kDNA-PCR, com os iniciadores 121 e 122, algumas amostras, incluindo o controle positivo para $T$. cruzi, amplificaram uma banda adicional de aproximadamente $600 \mathrm{pb}$, todavia, é suficiente dizer que a amostra é positiva quando é observado pelo menos um produto esperado (Haidamak et al., 2016). Alguns conjuntos de iniciadores permitem a presença de várias bandas devido à amplificação de mais de uma repetição de genes que ocorrem em múltiplas cópias em tandem (Desquesnes \& Dávila, 2002).

Em um estudo realizado no Distrito Federal do Brasil com animais silvestres, as reações de PCR obtidas utilizando os iniciadores S35 e S36 foi possível observar que esses iniciadores produziram um amplificado de $330 \mathrm{pb}$ quando estava presente o T. cruzi e um amplificado de 300 a 450 pb no controle positivo de Trypanosoma rangeli (Vallejo et al., 2003). T. rangeli não é patogênico, sendo encontrado na América Central e do Sul, áreas de 
sobreposição com $T$. cruzi, em que ambos os parasitos podem produzir infecções simultâneas nos hospedeiros e vetores (Meneguetti et al., 2014).

Devido a formação de grande quantidade de bandas na segunda condição, houve diminuição ainda mais na quantidade de primers, além de diminuir a quantidade de dNTP e Taq, conforme descrito para reação de terceira condição. Porém, ainda foi possível observar a amplificação de bandas inespecíficas, incluindo o controle positivo. Como a concentração de magnésio pode afetar o anelamento dos primers, em que o aumento de $\mathrm{MgCl}_{2}$ pode ter efeitos na especificidade e rendimento da amplificação (Innis \& Gelfand, 2012), foi realizada a reação de quarta condição. Contudo, ainda se visualizou à amplificação de bandas adicionais, incluindo o controle positivo em que ocorreu a formação de várias bandas inespecíficas.

Aumentar a temperatura de anelamento pode garantir uma vantagem competitiva com o alvo do amplicon (Hecker \& Roux, 1996). Realizou-se a quinta condição, em que houve a formação de bandas fracas e as amostras que anteriormente amplificaram foram negativas na quinta condição de PCR, em seguida se realizou a sexta condição de reação de PCR, porém houve a formação de bandas fracas. Se pouco ou nenhum produto for detectado sugere-se: adicionar, estender ou aumentar a temperatura do passo inicial de desnaturação antes do ciclo; realizar a nested-PCR; trocar o conjunto de primers utilizados por (Roux, 2009).

Analisando as seis condições de PCR, das 50 amostras que coincidiram o resultado nas diferentes PCRs 37 (74 \%; IC $95 \%$ : 59,66 - 85,37) houve amplificação da região míniciculo kDNA utilizando os primers 121 e 122. Dentre as quais, 10 (20\%; IC: $95 \%$; 10,03 - 33,72) positivas foram ordem Chiroptera, 12 (24\%; IC 95\%: 13,06 - 38,17) Didelphimorphia e 15 (30\%; IC 95\%: 17,86 - 44,61) Rodentia, sendo que a prevalência entre as ordens não foi estatisticamente significativamente $(\mathrm{G}=0,6234$; Valor de $\mathrm{P}=0,7322)$.

Em relação ao tipo de pool houve amplificação quando envolvia baço, coração, fígado, pulmões e rins, sendo que as amostras processadas com pulmões tiveram positividade 12,5 vezes maior do que o pool sem pulmões, ademais amostras de encéfalo foram negativas. Em relação ao mapa de distribuição espacial pela estimativa de densidade de Kernel para amostras de mamíferos silvestres que amplificaram através da técnica de kDNA-PCR indica as áreas que tiveram altas taxas de ocorrências de protozoário, entre elas a região de Igrapiúna com 20 positivos (83,33\%; IC 95\%: 62,62 - 95,26), Elísio Medrado com três positivos (42,86\%; IC 95\%: 9,90 - 81,59) e Varzedo com nove positivos (64,29\%; IC $95 \%: 35,14$ - 87,24) (Figura 1), a frequência entre elas não foi estatisticamente significante $(\mathrm{G}=4,3401 ; \mathrm{G} . \mathrm{L} .=2 ; \mathrm{p}=$ $0,1142)$.

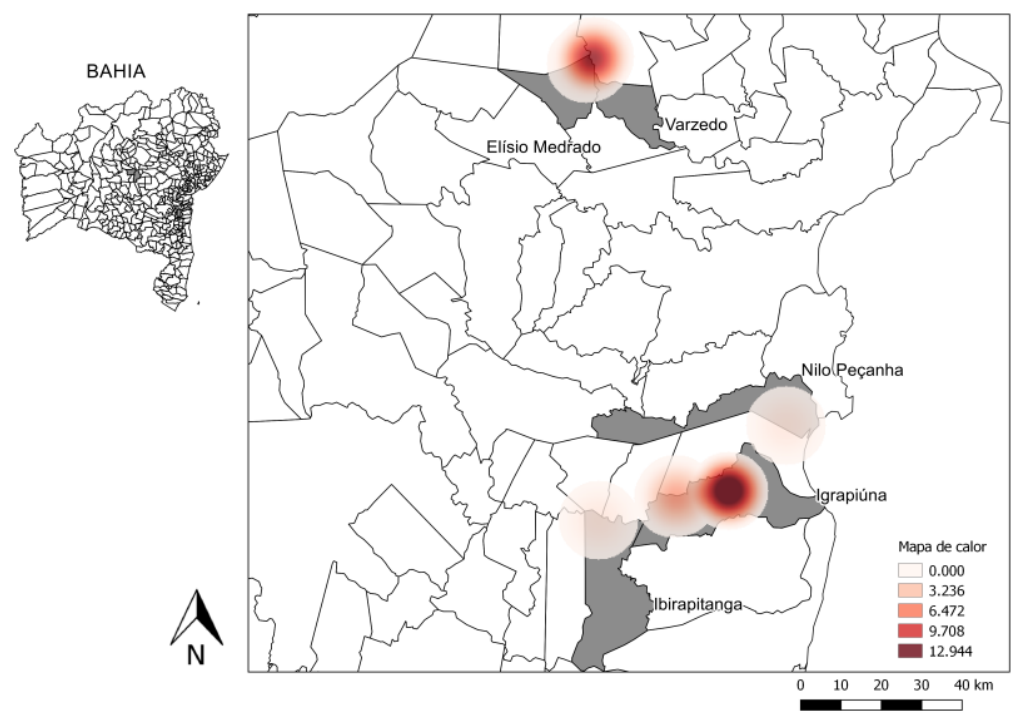

Figura 1. Mapa de estimativa de densidade de Kernel nas localidades de coleta a partir de tecidos de órgãos de mamíferos silvestres que amplificaram a região míniciculo kDNA utilizando os primers 121 e 122 . Feira de Santana, 2017. 


\section{CONSIDERAÇÕES FINAIS}

O presente estudo exibe a importância epidemiológica da investigação de Trypanosoma cruzi em mamíferos selvagens, sendo necessário o sequenciamento das amostras que amplificaram ou realizar outras condições de reação, como usar nested-PCR ou utilizar outros primers para identificação das possíveis linhagens do T. cruzi ou se existe outros Trypanosoma, como $T$. rangeli sendo amplificados com padrão de bandas diferentes.

\section{REFERÊNCIAS}

DE CARVALHO, M.; DE OLIVEIRA, T. 2015. Small non-volant mammals (Didelphimorphia and Rodentia) from the RPPN Guarirú, an Atlantic Forest fragment in northeastern Brazil. Check List. 11 (6): 1782.

DESQUESNES, M.; DAVILA, A. M. R. 2002. Applications of PCR-based tools for detection and identification of animal trypanosomes: a review and perspectives. Veterinary parasitology. 109 (3): 213-231.

HAIDAMAK, J.; SHIMADA, M. K.; DO ROCIO KLISIOWICZ, D.; REIFUR, L. 2016. Trypanosoma cruzi vector infection rate is underestimated in some localities in the state of Bahia. Revista Patologia Tropical.45 (1): 55-65.

INNIS, M.; GELFAND, D. 2012. Optimization of PCRs. Academic Press, San Diego, 481p. MACHADO, F. S.; DUTRA, W. O.; ESPER, L.; GOLLOB, K. J. 2012. Current understanding of immunity to Trypanosoma cruzi infection and pathogenesis of Chagas disease. Seminars in Immunopathology. 34 (6): 753-770.

MENEGUETTI, D.; SOARES, E.; CAMPANER, M.; CAMARGO, L. First report of Rhodnius montenegrensis (Hemiptera: Reduviidae: Triatominae) infection by Trypanosoma rangeli. 2014. Rev. Soc. Bras. Med. Trop. 47 (3): 374-376.

MIYAMOTO, C.; GOMES, M.; MARANGON, A.; ARAÚJO, S. et al. 2006. Trypanosoma cruzi: sensitivity of the polymerase chain reaction for detecting the parasite in the blood of mice infected with different clonal genotypes. Experimental Parasitology. 112 (3): 198-201.

ORTIZ, S.; ZULANTAY, I.; SOLARI, A.; BISIO, M. et al. 2012. Presence of Trypanosoma cruzi in pregnant women and typing of lineages in congenital cases. Acta Tropica. 124 (3): 243-249.

OROZCO, M.; ENRIQUEZ, G.; CARDINAL, M.; PICCINALI, R. et al. 2016. A comparative study of Trypanosoma cruzi infection in sylvatic mammals from a protected and a disturbed area in the Argentine Chaco. Acta tropica. 155: 34-42.

RAMÍREZ, J; DUQUE, M.; MONTILLA, M.; CUCUNUBÁ, Z. et al. 2012. Multilocus PCR-RFLP profiling in Trypanosoma cruzi I highlights an intraspecific genetic variation pattern. Infection, Genetics and Evolution. 12 (8): 1743-1750.

ROCHA, F.; ROQUE, A.; DE LIMA, J.; CHEIDA, C. 2013. Trypanosoma cruzi infection in neotropical wild carnivores (Mammalia: Carnivora): at the top of the T. cruzi transmission chain. PloS One. 8 (7): e67463.

ROUX, K. H. 2009. Optimization and troubleshooting in PCR. Cold Spring Harbor Protocols. 2009 (4): 1-6.

VAGO, A.; ANDRADE, L.; LEITE, A.; REIS, D. et al. 2000. Genetic characterization of Trypanosoma cruzi directly from tissues of patients with chronic Chagas disease: differential distribution of genetic types into diverse organs. The American Journal of Pathology. 156 (5): 1805-1809.

VALLEJO, G.; GUHL, F.; CARRANZA, J.; MORENO, J. et al. 2003. Parity between kinetoplast DNA and mini-exon gene sequences supports either clonal evolution or speciation in Trypanosoma rangeli strains isolated from Rhodnius colombiensis, R. pallescens and $R$. prolixus in Colombia. Infection, Genetics and Evolution. 3 (1): 39-45. 